\title{
Antibacterial, cytotoxic and trypanocidal activities of marine-derived fungi isolated from Philippine macroalgae and seagrasses
}

\author{
Kin Israel Notarte ${ }^{1,2,3^{*}}$, Takashi Yaguchi ${ }^{4}$, Keisuke Suganuma ${ }^{5}$, Thomas Edison dela Cruz ${ }^{1,2,3^{*}}$ \\ ${ }^{1}$ The Graduate School, ${ }^{2}$ College of Science and ${ }^{3}$ Fungal Biodiversity, Ecogenomics and Systematics Group, Research \\ Center for the Natural and Applied Sciences, University of Santo Tomas, España 1008, Manila, Philippines \\ ${ }^{4}$ Medical Mycology Research Center, Chiba University, 1-8-1 Inohana, Chuo-ku, Chiba 260-8673, Japan \\ ${ }^{5}$ National Research Center for Protozoan Diseases, Obihiro University of Agriculture and Veterinary Medicine, Inada, \\ Obihiro, Hokkaido 080-8555, Japan
}

\begin{abstract}
The occurrence and bioactivities of marine-derived fungi are evaluated in this paper. A total of 16 morphospecies of marine-derived fungi (MDF) were isolated from four host macroalgae and two seagrasses and identified as belonging to the genera Aspergillus, Fusarium, Paecilomyces, Penicillium, Sclerotinia, Thamnidium and Trichoderma, including five mycelia sterilia. Among these host organisms, the rhodophyte Laurencia intermedia harboured the highest number of isolated MDF. Selected MDF were then assayed and showed to inhibit Pseudomonas aeruginosa (8-19 mm zone of inhibition) and Staphylococcus aureus (6-19 mm zone of inhibition), and were cytotoxic against the brine shrimp Artemia salina nauplii $\left(\mathrm{LD}_{50}: 201.56-948.37 \mu \mathrm{g} \mathrm{mL} \mathrm{L}^{-1}\right)$. The screening led to the selection of five of the most bioactive morphospecies, all belonging to the genus Aspergillus. These marine aspergilli were subjected to $\beta$-tubulin gene sequence analysis for species identification, and to mass production in different culture media with or without marine salts, and screening of the crude culture extracts for their cytotoxic and trypanocidal activities. Aspergillus tubingensis cultivated in potato dextrose broth with marine salt proved to be the most cytotoxic against P388 ( $\mathrm{IC}_{50}: 1028 \mathrm{ng} \mathrm{mL}^{-1}$ ) and HeLa $\left(\mathrm{IC}_{50}: 1301 \mathrm{ng} \mathrm{mL}^{-1}\right) \mathrm{cancer}$ cells. On the other hand, A. fumigatus cultivated in malt extract broth without marine salt was shown to be the most potent against Trypanosoma congolense $\left(\mathrm{IC}_{50}: 298.18 \mathrm{ng} \mathrm{mL} \mathrm{m}^{-1}\right.$ ). Our study therefore showed that salinity may influence the bioactivities of some species of MDF.
\end{abstract}

Key words: bioactivity, fungal natural products, marine fungi, Philippines

Abbreviations: ASW - artificial seawater; DMSO - dimethyl sulfoxide; MDF - marine-derived fungi; MEA - malt extract agar; MEAS - malt extract agar with marine salt; MEB - malt extract broth; MEBS - malt extract broth with marine salt; PDB - potato dextrose broth; PDBS - potato dextrose broth with marine salt; ZOI - zone of inhibition

\section{Introduction}

The ocean has vast biological resources, accounting for more than eighty percent of total world biodiversity, which makes it a reservoir for many kinds of organisms, including marine-derived fungi (Bugni and Ireland 2004). These marine-derived fungi (MDF) grow and possibly sporulate in the marine ecosystem (Kohlmeyer and Kohlmeyer 1979). Interestingly, many of these marine-derived fungi produce structurally diverse and bioactive compounds (dela Cruz et al. 2006a, Schulz et al. 2008, Silber et al. 2016), utilized varied substrata (dela Cruz et al. 2006b), and may play an important ecological role in marine habitats (Solis et al. 2010). In spite of their economic and ecological importance, some of the less explored MDF thrive inside healthy tissues of macroalgae, e.g. in Sargassum thunbergii (Miao et al. 2012), and seagrasses, such as Cymodocea serrulata and Halophila ovalis (Supaphon et al. 2013).

\footnotetext{
* Corresponding authors, e-mails: kinotarte@gmail.com, tedelacruz@ust.edu.ph
} 
Various biochemical properties with anti-infective and anti-tumor activities have also been documented in algaeand seagrass-derived marine fungi (Greve et al. 2008, Supaphon et al. 2013, 2014). For instance, Aspergillus flavus isolated from the green alga Enteromorpha tubulosa synthesized two new 5-hydroxy-2-pyrone derivatives that could induce production of cAMP on GPR12-transfected cells (Lin et al. 2008). Penicillium chrysogenum isolated from the red alga Laurencia produced the novel antifungal and cytotoxic penicisteroids A and B (Gao et al. 2011). Despite the promising chemicals that these fungi produce, there are no drugs from these fungi that have been commercially approved (Gerwick and Moore 2012). Obviously, this necessitates the need to do more research on these organisms in order to find bioactive and potentially novel chemicals for drug discovery and development. Thus, this recent study isolated marine-derived fungi in Philippine macroalgae and seagrasses, and tested their biological activities for potential chemotherapeutic uses.

\section{Materials and methods}

\section{Screening of marine-derived fungi for biological activities}

\section{Collection of macroalgae and seagrasses}

Four species of algae, belonging to Phaeophyta [Sargassum piluliferum (Turner) C. Agardh], Chlorophyta [Caulerpa racemosa (Forsskål) J. Agardh], and Rhodophyta [Laurencia intermedia Yamada and Portieria hornemannii (Lyngbye) P. C. Silva], and two species of seagrasses, Enhalus acoroides (Linnaeus) Royle and Syringodium isoetifolium (Ascherson) Dandy, were collected from the intertidal $\left(9^{\circ} 19^{\prime} 15.82^{\prime \prime} \mathrm{N}\right.$, $\left.123^{\circ} 18^{\prime} 45.56^{\prime \prime} \mathrm{E}\right)$ and subtidal $\left(9^{\circ} 19^{\prime} 15.82^{\prime \prime} \mathrm{N}, 123^{\circ} 18^{\prime} 46.53^{\prime \prime} \mathrm{E}\right)$ zones of Piapi Beach, Dumaguete City, Negros Oriental, Philippines. The collected specimens were washed three times with filtered seawater (FSW) to get rid of adhering soil and epiphytes. These were placed in clean ziplock bags containing an ample amount of FSW. The samples were kept on ice and processed in the laboratory within $48 \mathrm{~h}$. Identification of the host algae and seagrasses was done following detailed morphological characterization of voucher specimens.

Isolation and identification of marine-derived fungi

The thalli, roots, fronds and leaves of the collected algae or seagrasses were initially washed with sterile artificial seawater (ASW, 33 g marine salt dissolved in 1L distilled water). With a sterile razor blade, the specimens were cut into 3-5 mm explants and immersed in 70\% ethanol (EtOH) for $60 \mathrm{~s}$ to remove surface-associated microorganisms. The explants were then washed three times with sterile ASW for 3 min and blotted dry with sterile cotton cloth. Afterwards, the explants were transferred onto petri plates pre-filled with $1 / 2$-strength malt extract agar containing $33 \mathrm{~g} \mathrm{~L}^{-1}$ marine salt (MEAS). To prevent growth of contaminating bacteria, the culture media were supplemented with streptomycin (450 $\left.\mu \mathrm{g} \mathrm{mL} \mathrm{m}^{-1}\right)$. Six explants were placed on each culture plate. In all, five plates containing a total of 30 explants were used for each algal or seagrass species collected. Tissue printing was performed by carefully placing some of the explants over the surface of MEAS plates using sterilized tweezers to evaluate the effectivity of the surface-sterilization treatment. For sterility control, two uninoculated plates were exposed to the working environment to rule out air contamination. The culture plates were incubated for 1 week at room temperature and were monitored daily for fungal growth. Fungal colonies that grew out of the edges of the explants were subcultured on freshly prepared full-strength MEAS and purified by spore touch technique. Identification of isolates was achieved by comparing their colony, hyphal, and spore morphologies with the published literature, i.e. Klinch (2002), Raper and Fennell (1977), and Quimio (1988). To test if the isolated fungi were adapted to the marine environment, the colony extension rate (CER) for the isolates grown in MEA with or without salt was computed using the formula: [mean colony radial growth (day 7) - mean colony radial growth (day 3)] / number of days of incubation (4 days). A paired ttest was computed for the CER on MEA and MEAS to determine if the presence or absence of marine salt in the medium significantly affected the colony extension rate of the MDF.

\section{Mass production and extraction of metabolites}

Twenty-one MDF were mass produced by transferring an agar block cut from the margin of a 7-day old fungal colony onto Erlenmeyer flasks containing $100 \mathrm{~mL}$ malt extract broth supplemented with $33 \mathrm{~g} \mathrm{~L}^{-1}$ marine salt (MEBS). A total of five culture flasks were prepared for each fungal isolate and were maintained in stationary condition at room temperature for 4 weeks. Following incubation, the contents of the culture flasks coming from the same fungal isolate were pooled and extraction of secondary metabolites was performed by initially separating the broth and mycelia. The culture broth was extracted with ethyl acetate in 1:1 (v/v) proportion, while the harvested mycelia were homogenized and then soaked in methanol. The ethyl acetate and methanol extracts were concentrated in vacuo and stored in preweighed vials.

\section{Screening for antibacterial activities}

The test bacteria (Staphylococcus aureus ATCC 25923, Escherichia coli ATCC 25922, and Pseudomonas aeruginosa ATCC 27853) were acquired from the University of Santo Tomas Collection of Microbial Strains (USTCMS), Manila, Philippines and maintained on tryptic soy broth (TSB). Following the protocol of Quinto and Santos (2005), the 24-h old bacterial cultures were transferred to tubes containing $5 \mathrm{~mL}$ of $0.9 \%$ normal saline solution (NSS) and standardized to $0.5 \mathrm{McF}$ arland. Then, a sterile swab was dipped on the cell suspension and streaked onto Mueller Hinton agar (MHA) plates. The crude extracts from the mycelia and culture broth were weighed and dissolved in DMSO to achieve a concentration of $50 \mathrm{mg} \mathrm{mL}^{-1}$. The sterile Whatman paper disks (6 $\mathrm{mm}$ in diameter) were then impregnated with 20 $\mu \mathrm{L}$ of crude extracts and air-dried aseptically, giving a final concentration of $1 \mathrm{mg}$ per disk of extract. The treated paper 
disks were placed on top of the MHA plate seeded with the test bacteria. The control antibiotic was streptomycin $(10 \mu \mathrm{g})$ while the negative control was DMSO. All culture plates (in triplicates) were incubated at $37^{\circ} \mathrm{C}$ for $24 \mathrm{~h}$ and the zone of inhibition (ZOI) was measured in $\mathrm{mm}$. The observed zone of inhibition was then compared with the controls and the reference antibiotics listed in EUCAST Ver. 7 (2017).

Screening for brine shrimp cytotoxicity

Dried cysts of Artemia salina were hatched in ASW (1 g cyst per liter) at room temperature with continuous illumination. ASW was prepared by dissolving $38 \mathrm{~g}$ of commercially available marine salt in distilled water. After hatching, the nauplii were collected with a pipette and concentrated in a vial. The testing of fungal culture extracts was conducted in 6-well microplates. The stock solution was prepared by dissolving the extracts in DMSO at $5 \mathrm{mg} \mathrm{mL}^{-1}$. Aliquots of $0.10,0.20,0.40,0.60,0.80$, and $1 \mathrm{~mL}$ of stock solution were diluted with $4.90,4.80,4.60,4.40,4.20$, and $4 \mathrm{~mL}$ of brine water to make up a final concentration for the extracts of $100,200,400,600,800$, and $1000 \mu \mathrm{g} \mathrm{mL}^{-1}$, respectively. The negative control was DMSO. Ten brine shrimps were then carefully transferred to each well with a pipette and these were incubated with the fungal culture extracts for $24 \mathrm{~h}$. The treatments and the control were tested in triplicate, and the number of nauplii that survived was counted for $\mathrm{LD}_{50}$ determination using probit regression analysis at 95\% confidence interval.

\section{Effects of salinity and culture media on the bioactivities of marine aspergilli}

Selection and molecular characterization of marine aspergilli

The marine aspergilli were selected based on the results of the disk diffusion and the brine shrimp cytotoxicity assays. Identification of these strains was done via molecular methods. The DNA of the five marine aspergilli was extracted using the Gentorukun ${ }^{\oplus}$ (Takara Bio Inc., Ltd., Otsu, Japan) from approximately $100 \mu \mathrm{L}$ volume of fungal mass cultured at $25^{\circ} \mathrm{C}$ for 5 days on potato dextrose agar (PDA) slants. The $\beta$-tubulin gene was sequenced directly from PCR products using Bt2a (5'-ggtaaccaaatcggtgctgctttc-3') and Bt $2 b$ (5'-accctcagttgagtgaccttggc-3') primer pair (Glass and Donaldson 1995). The PCR conditions consisted of denaturation at $95^{\circ} \mathrm{C}$ for $10 \mathrm{~min}$ followed by 35 cycles of $95^{\circ} \mathrm{C}$ for $1 \mathrm{~min}$, $55^{\circ} \mathrm{C}$ for $1 \mathrm{~min}$, and $72^{\circ} \mathrm{C}$ for $1 \mathrm{~min}$, with a final extension at $72^{\circ} \mathrm{C}$ for $10 \mathrm{~min}$. The PCR products were then sequenced using the Bigdye terminator cycle sequencing ready reaction kit (Applied Biosystems, Foster City, CA, USA) on an ABI PRISM $^{\oplus} 3130 \mathrm{ABI}$ Genetic analyzer (Applied Biosystems) and the DNA sequences were edited using ATGC Ver. 4 sequence assembly software (Genetyx Co., Tokyo, Japan). Using the BLAST algorithm, the $\beta$-tubulin gene sequence was used to search the GenBank database at the NCBI website (http:// blast.ncbi.nlm.nih.gov/Blast.cgi). The phylogenetic tree was then constructed using the consensus sequence based on PAUP maximum parsimony analysis.
Mass production and extraction of metabolites from marine aspergilli

Five selected species of marine aspergilli were mass produced in solid rice medium and the liquid media, malt extract broth (MEB/MEBS) and potato dextrose broth (PDB/ PDBS) with and without marine salt. A total of five Erlenmeyer flasks each containing $100 \mathrm{~mL}$ of culture media were prepared for each marine aspergillus. These were maintained under stationary conditions at room temperature for 4 weeks. For the marine aspergilli cultivated in the liquid media, the culture broth and the fungal mycelia were separated following incubation. The culture broth was extracted with ethyl acetate in 1:1 (v/v) proportion while the mycelia were homogenized and soaked in methanol. For the marine aspergilli cultivated in solid rice medium, only ethyl acetate extraction was performed. The ethyl acetate and methanol extracts were concentrated in vacuo and stored in preweighed vials.

\section{Methyl thiol tetrazolium (MTT) cytotoxicity assay}

Following the protocol of Takada et al. (2012), HeLa cervical cancer cells were cultured in Dulbecco's modified eagle medium (Wako Pure Chemical Industries, Osaka, Japan), containing $10 \%$ fetal bovine serum, $2 \mathrm{mg} \mathrm{mL}^{-1}$ gentamycin, and $10 \mathrm{mg} \mathrm{mL}^{-1}$ antibiotics adjusted to $\mathrm{pH} 7.0-7.4$ by $1 \mathrm{M}$ $\mathrm{HCl}$, while $\mathrm{P} 388$ murine leukemia cancer cells were cultivated in Roswell Park Memorial Institute Medium-1640 (Wako Pure Chemical Industries), containing 10\% fetal bovine serum, $100 \mathrm{mg} \mathrm{mL}^{-1}$ kanamycin, and $10 \mathrm{mM}$ 2-hydroxyethyldisulfide. The cell lines were incubated at $37^{\circ} \mathrm{C}$ under an atmosphere of $5 \% \mathrm{CO}_{2}$. Afterwards, an aliquot of $200 \mu \mathrm{L}$ tumor cell suspension $\left(1 \times 10^{4}\right.$ cells $\left.\mathrm{mL}^{-1}\right)$ was dispensed unto each well of the 96-well microplate and pre-incubated for $24 \mathrm{~h}$. Following pre-incubation, $1 \mu \mathrm{L}$ of marine aspergilli extracts dissolved in DMSO concentrated at $1 \mathrm{mg} \mathrm{mL}^{-1}$ was added to the cell suspension to prepare a screening concentration of 5 $\mu \mathrm{g} \mathrm{mL} \mathrm{L}^{-1}$. The reference chemotherapeutic drug was adriamycin. After treatment, the cells were further incubated for 72 $\mathrm{h}$ and to each well $50 \mu \mathrm{L}$ of 3-(4,5-dimethyl-2-thiazolyl)-2,5diphenyl-2H-tetrazolium bromide (MTT) saline solution (1 $\mathrm{mg} \mathrm{mL} \mathrm{m}^{-1}$ ) was added, followed by incubation for $3 \mathrm{~h}$ under the same condition to stain live cells. Finally, the culture medium was withdrawn and $150 \mu \mathrm{L}$ of DMSO was added to dissolve cells. Using the Fusion ${ }^{\mathrm{TM}} \alpha$ microplate reader (Packard Bioscience Company, CT, USA), the absorbance of each well was read. The $\mathrm{IC}_{50}$ for the most bioactive aspergilli extracts was calculated by plotting a dose-dependent curve in GraphPad PRISM 5 software (GraphPad Software Inc., CA, USA).

ATP-based luciferase viability assay for Trypanosoma congolense

Following the protocol of Suganuma et al. (2014), the blood stream form of Trypanosoma congolense IL 3000 was cultivated at $33{ }^{\circ} \mathrm{C}$ in air using Iscove's modified Dulbecco's medium (Sigma-Aldrich, Tokyo, Japan), containing 20\% heat inactivated-fetal bovine serum, 60 mM HEPES, 
$1 \mathrm{mM}$ pyruvic acid sodium salt, $0.1 \mathrm{mM}$ bathocuproine, $1 \mathrm{mM}$ hypoxanthine, $16 \mu \mathrm{M}$ thymidine, $10 \mu \mathrm{g} \mathrm{\textrm {L } ^ { - 1 }}$ insulin, $5.5 \mu \mathrm{g} \mathrm{L}^{-1}$ transferrin, $6.7 \mathrm{ng} \mathrm{L}^{-1}$ sodium selenite, $0.0001 \%$ 2- $\beta$-mercaptoethanol, $0.4 \mathrm{~g} \mathrm{~L}^{-1} \mathrm{BSA}$, and $2 \mathrm{mM}$ L-cysteine. The screening concentration for the fungal extracts was set at $2.5 \mu \mathrm{g} \mathrm{mL} \mathrm{m}^{-1}$. This was prepared by initially diluting 0.5 $\mu \mathrm{L}$ of fungal crude extract $\left(1 \mathrm{mg} \mathrm{mL}^{-1}\right)$ with $100 \mu \mathrm{L} \mathrm{HMI-}$ 9. From this solution, a $50-\mu \mathrm{L}$ aliquot was dispensed to the microplate and added to each well containing $50 \mu \mathrm{L}$ suspension of $T$. congolense $\left(2 \times 10^{5}\right.$ cells $\left.\mathrm{mL}^{-1}\right)$. The reference antiprotozoal drug was pentamidine. The microplates were incubated for $72 \mathrm{~h}$, and subsequently, $50 \mu \mathrm{L}$ of CellTiter-Glo ${ }^{\oplus}$ luminescent cell viability assay reagent (Promega Japan, Tokyo, Japan) was added to each well to evaluate ATP concentration. Following the incubation of the microplates for another $10 \mathrm{~min}$ at room temperature, luminescence was read using a GloMax ${ }^{\circledast}$-Multi Detection System plate reader (Promega Japan, Tokyo, Japan). The $\mathrm{IC}_{50}$ values of the most bioactive aspergilli extracts were computed by plotting a dosedependent curve in GraphPad PRISM 5 software (GraphPad Software Inc.). Moreover, the selectivity index (SI) of the bioactive extracts was also calculated following the formula of Koch et al. (2005): $\mathrm{IC}_{50}$ HeLa or P388 / IC 50 Trypanosoma congolense.

\section{Results}

Occurrence of marine-derived fungi in macroalgae and seagrasses

A total of $40 \mathrm{MDF}$ were isolated from algae and seagrasses collected from Piapi Beach, Philippines. These MDF belonged to 16 morphospecies from the genera Aspergillus, Fusarium, Paecilomyces, Penicillium, Sclerotinia, Thamnidium, and Trichoderma (Tab. 1). Among these genera, Aspergillus was isolated in the highest frequency. Five of the MDF could not be identified as they remained sterile even after prolonged incubation, hence were simply designated as $m y$ celia sterilia. Among the host macroalgae and seagrasses, the red alga $L$. intermedia harbored the highest number of isolates, followed by the seagrass E. acoroides, then the brown alga $S$. piluliferum, and the seagrass S. isoetifolium. Intrigu- ingly, only one MDF was isolated from the red alga P. hornemannii and from the green alga C. racemosa.

The identified fungal genera were known to be of terrestrial origin. Hence, to assess the adaptability of the isolates in the marine environment, the MDF were cultured in MEA with or without marine salt. Of the $21 \mathrm{MDF}$ tested, 17 grew much better in MEAS than in MEA (Fig. 1). Statistical analysis by one-tailed paired t-test confirmed that the mean colony extension rates in MEAS were greater than MEA and that the difference was highly significant ( $p$-value 0.000349 $<\alpha=0.01)$.

Antibacterial and cytotoxic activities of marine-derived fungi

Several MDF showed antibacterial properties and brine shrimp cytotoxicity (Tab. 2). Of the 21 MDF tested, five fungal isolates belonging to the genus Aspergillus and one mycelia sterilia inhibited P. aeruginosa and/or S. aureus with ZOI greater than $10 \mathrm{~mm}$. The most bioactive crude extracts were the mycelial extract of $A$. fumigatus against $P$. aeruginosa (19 $\mathrm{mm} Z \mathrm{ZOI}$ ) and the broth extract of $A$. tubingensis against $S$. aureus (19 mm ZOI). The ZOI of the most bioactive culture extracts were comparable to the control antibiotic streptomycin (18 - $21 \mathrm{~mm}$ ZOI) and with some reference antibiotics listed in EUCAST Ver. 7 (2017). Interestingly, no antagonism to E. coli treated with the MDF culture extracts was observed. Meanwhile, of the $21 \mathrm{MDF}$ tested for cytotoxicity, seven MDF, belonging to the genera Aspergillus, Fusarium, Paecilomyces, Penicillium and Trichoderma, proved to be cytotoxic to A. salina nauplii with $\mathrm{LD}_{50}$ ranging from 201.56$948.37 \mu \mathrm{g} \mathrm{mL}^{-1}$. The most cytotoxic was $A$. tubingensis. Thus, members of the genus Aspergillus were noted to be generally bioactive in this study. Furthermore, there was higher record of bioactivities with the ethyl acetate extracts derived from the fungal culture broth as opposed to the methanolic extracts derived from the fungal mycelia.

\section{Molecular characterization of marine aspergilli}

The marine aspergilli that showed promising bioactivities in the previous screening were subjected to molecular characterization to validate their identity. Comparison of their $\beta$-tubulin gene sequences by Blast searching showed

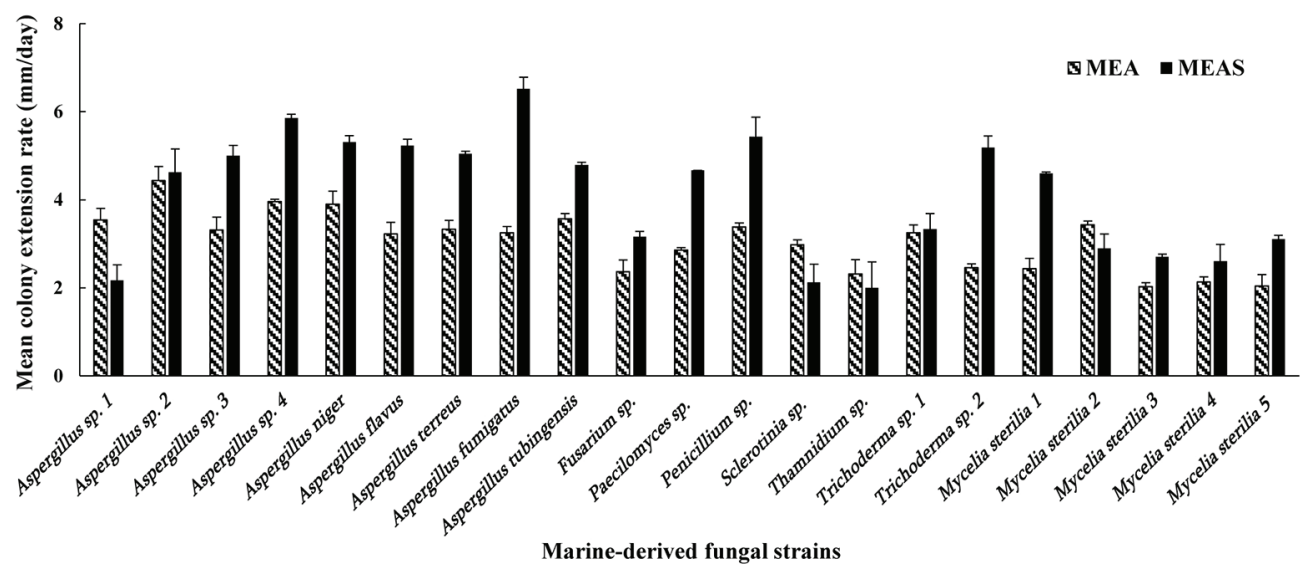

Fig. 1. Colony extension rates of marine-derived fungi grown on malt extract agar with (MEAS) or without (MEA) marine salt ( $\mathrm{n}=3$ ). Mean standard deviation is expressed in error bar. 
Tab. 1. Marine-derived fungi (MDF) isolated from macroalgae and seagrasses collected from Piapi Beach, Dumaguete City, Philippines. ${ }^{a}$ Names in bold grew better in malt extract agar with salt. Names with asterisks were isolated in more than one host alga/seagrass.

\begin{tabular}{|c|c|c|c|}
\hline Host alga/seagrass & Substrata & Marine-derived fungi ${ }^{a}$ & $\begin{array}{c}\text { Total no. of } \\
\text { isolated MDF }\end{array}$ \\
\hline $\begin{array}{l}\text { Laurencia intermedia } \\
\text { (Rhodophyte) }\end{array}$ & Thallus & $\begin{array}{l}\text { Aspergillus sp. } 1^{*} \\
\text { Aspergillus sp. } 2 \\
\text { Aspergillus flavus } \\
\text { Aspergillus terreus } \\
\text { Fusarium sp. } \\
\text { Thamnidium } \mathrm{sp.} \\
\text { Trichoderma sp. } 1^{\star} \\
\text { Trichoderma sp. } 2^{\star} \\
\text { Mycelia sterilia } 1 \\
\text { Mycelia sterilia } 2\end{array}$ & 13 \\
\hline $\begin{array}{l}\text { Portieria hornemannii } \\
\text { (Rhodophyte) }\end{array}$ & Thallus & Mycelia sterilia 3 & 1 \\
\hline $\begin{array}{l}\text { Sargassum piluliferum } \\
\text { (Phaeophyte) }\end{array}$ & Frond & $\begin{array}{l}\text { Aspergillus sp. } 1^{*} \\
\text { Aspergillus flavus }\end{array}$ & 4 \\
\hline & Thallus & $\begin{array}{l}\text { Aspergillus fumigatus } \\
\text { Fusarium sp. }{ }^{*} \\
\text { Trichoderma sp. } 2^{\star}\end{array}$ & 4 \\
\hline $\begin{array}{l}\text { Caulerpa racemosa } \\
\text { (Chlorophyte) }\end{array}$ & Thallus & Aspergillus niger & 2 \\
\hline \multirow[t]{2}{*}{$\begin{array}{l}\text { Enhalus acoroides } \\
\text { (Seagrass) }\end{array}$} & Root & $\begin{array}{l}\text { Paecilomyces sp. } \\
\text { Trichoderma sp. } 1^{\star}\end{array}$ & 4 \\
\hline & Leaf & $\begin{array}{l}\text { Aspergillus sp. } 1^{\star} \\
\text { Aspergillus } \mathrm{sp} .3 \\
\text { Aspergillus tubingensis } \\
\text { Mycelia sterilia } 4 \\
\text { Mycelia sterilia } 5^{\star}\end{array}$ & 6 \\
\hline $\begin{array}{l}\text { Syringodium isoetifolium } \\
\text { (Seagrass) }\end{array}$ & Leaf & $\begin{array}{l}\text { Aspergillus sp. } 4 \\
\text { Paecilomyces sp. }{ }^{*} \\
\text { Penicillium sp. } \\
\text { Sclerotinia sp. } \\
\text { Mycelia sterilia } 5^{\star}\end{array}$ & 6 \\
\hline
\end{tabular}

$100 \%$ similarities between the sequences of the isolated marine aspergilli and those deposited at GenBank. This homology was further supported by their phylogenetic tree constructed according to maximum parsimony analysis with bootstrap values $90 \%$ and above (Fig. 2). Molecular analysis confirmed the marine aspergilli isolates as A. fumigatus
(AF-ST-02), A. flavus (AF-SL-02), A. niger (AF-C-01), A. terreus (AF-L-12) and $A$. tubingensis (SF-EL-06). All the DNA sequences were deposited at the DNA Data Bank of Japan (DDBJ) with the accession number LC176429 for A. terreus, LC176430 for A. niger, LC176431 for A. flavus, LC176432 for A. fumigatus, and LC168474 for A. tubingensis. 


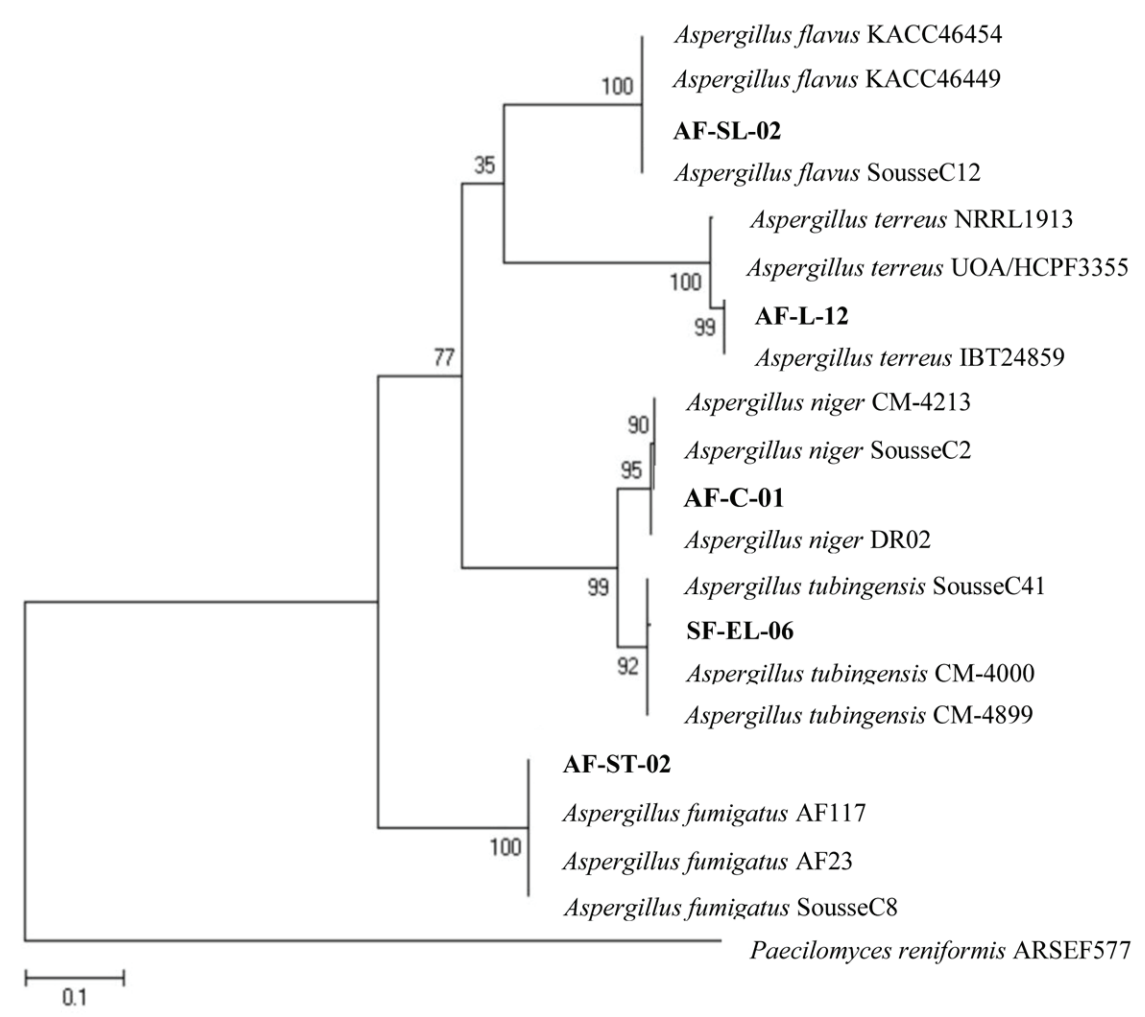

Fig. 2. Phylogenetic analysis of marine aspergilli. The consensus sequence was downloaded from GenBank and can be retrieved through the following accession numbers: A. flavus KACC46454 (KT354303.1), A. flavus KACC46449 (KT354304.1), A. flavus Sousse C12 (KJ136090.1), A. terreus NRRL1913 (EF669518.1), A. terreus UOA/HCPF3355 (GQ376127.1), A. terreus IBT24859 (FJ491707.1), A. niger CM4213 (FJ828913.1), A. niger Sousse C2 (KJ136065.1), A. niger DR02 (KC311845.1), A. tubingensis Sousse C41 (KJ136086.1), A. tubingensis CM4000 (KJ136086.1), A. tubingensis CM4899 (KJ136086.1), A. fumigatus AF117 (KF410677.1), A. fumigatus AF23 (KF410682.1) and A. fumigatus Sousse C8 (KJ136109.1).

Effects of culture media to the cytotoxicity of marine aspergilli

A total of 45 culture extracts were obtained from the marine aspergilli cultivated in five different media with and without marine salt. Of the marine aspergilli tested at $5 \mu \mathrm{g}$ $\mathrm{mL}^{-1}$ screening concentration, $A$. tubingensis and A. fumigatus were shown to be the most cytotoxic against cancer cells (Fig. 3). The ethyl acetate crude extracts of $A$. tubingensis derived from the culture media supplemented with salt (MEBS and PDBS) had a percent inhibition ranging from 98-99\% against P388 and from 70-76\% against HeLa. The bioactivity of these extracts against P388 was comparable with the chemotherapeutic drug adriamycin, which completely inhibited the cancer cell lines. Interestingly, the crude extracts derived from the same fungus cultivated in media without salt (MEB, $\mathrm{PDB}$ and solid rice) provided less inhibition, which ranged from $21-76 \%$ for both cancer cell lines. For A. fumigatus, the ethyl acetate crude extract derived from MEB was the most active with 62.81 and $68.55 \%$ inhibition for HeLa and P388, respectively. For the other marine aspergilli, A. niger, $A$. terreus, and $A$. flavus showed an inhibitory activity of less than $40 \%$ for both cancer cells regardless of whether the fungi were cultivated in media with or without marine salt and of whether the extracting solvent was methanol or ethyl acetate. Based on the initial screening of 45 extracts, four candidate extracts derived from A. fumigatus and A. tubingensis were selected for $\mathrm{IC}_{50}$ determination (Tab. 3). In this study, only the crude culture extracts with more than $50 \%$ inhibition were considered for $\mathrm{IC}_{50}$ determination. The most bioactive was the ethyl acetate extract of $A$. tubingensis mass produced in PDBS with an $\mathrm{IC}_{50}$ at $1028 \mathrm{ng} \mathrm{mL}^{-1}$ for P388 and $1301 \mathrm{ng}$ $\mathrm{mL}^{-1}$ for HeLa.

Effects of culture media to the trypanocidal activity of marine aspergilli

Consistent with the results of the cytotoxicity assay, $A$. tubingensis and $A$. fumigatus showed the highest trypanocidal activity at $2.5 \mu \mathrm{g} \mathrm{mL} \mathrm{m}^{-1}$ screening concentration (Fig. 4). The crude ethyl acetate extracts of $A$. tubingensis cultivated in media with salt (MEBS and PDBS) demonstrated an inhibitory activity of $99 \%$ comparable with the antiprotozoal drug pentamidine. In contrary, the crude extracts derived from the same fungus cultivated in media without salt (MEB, PDB and solid rice) showed lesser or no inhibitory activity that ranged from $0.53-87.75 \%$. On the other hand, only one extract from A. fumigatus showed promising activity. The crude ethyl acetate extract of the same fungus in MEB exhibited an inhibitory activity of $99 \%$, while the remaining extracts from other media provided an inhibitory activity of less than 55\%. A. niger, A. flavus, and A. terreus gave an inhibitory activity of less than $52 \%$ regardless of culture 
Tab. 2. Results of the disk diffusion and brine shrimp cytotoxicity assays of the crude ethyl acetate (EtOAc) and methanolic (MeOH) extracts from marine-derived fungi $(\mathrm{n}=3)$. ${ }^{\text {ZZOI }}$ assessment: inactive $<10 \mathrm{~mm}$; partially active $10-13 \mathrm{~mm}$; active $14-19 \mathrm{~mm}$; very active $>19 \mathrm{~mm}$ (Quinto and Santos 2005). ${ }^{\mathrm{b}} \mathrm{LD}_{50}$ assessment: cytotoxic $<1000 \mu \mathrm{g} \mathrm{mL} \mathrm{m}^{-1}$; non-cytotoxic $>1000 \mu \mathrm{g} \mathrm{mL} \mathrm{m}^{-1}$ (Meyer et al. 1982).

\begin{tabular}{|c|c|c|c|c|c|c|c|c|}
\hline \multirow{3}{*}{ Marine-derived fungi } & \multicolumn{6}{|c|}{ Test bacteria zone of inhibition - ZOI $(\mathrm{mm})^{\mathrm{a}}$} & \multirow{2}{*}{\multicolumn{2}{|c|}{$\begin{array}{l}\text { Brine shrimp assay } \\
\left.\mathrm{LD}_{50}(\mu \mathrm{g} \mathrm{mL})^{-1}\right)^{\mathrm{b}}\end{array}$}} \\
\hline & \multicolumn{2}{|c|}{ Pseudomonas aeruginosa } & \multicolumn{2}{|c|}{ Staphylococcus aureus } & \multicolumn{2}{|c|}{ Escherichia coli } & & \\
\hline & EtOAc & $\mathrm{MeOH}$ & EtOAc & $\mathrm{MeOH}$ & EtOAc & $\mathrm{MeOH}$ & EtOAc & $\mathrm{MeOH}$ \\
\hline \multicolumn{9}{|l|}{$\begin{array}{l}\text { Laurencia intermedia } \\
\text { (Rhodophyte) }\end{array}$} \\
\hline Aspergillus sp. 1 & 0 & 0 & 0 & 0 & 0 & 0 & $>1000$ & $>1000$ \\
\hline Aspergillus sp. 2 & 0 & 0 & 0 & 0 & 0 & 0 & $>1000$ & $>1000$ \\
\hline Aspergillus flavus & 13 & 0 & 10 & 0 & 0 & 0 & 836.24 & 948.37 \\
\hline Aspergillus terreus & 8 & 0 & 10 & 0 & 0 & 0 & 824.71 & 857.75 \\
\hline Thamnidium sp. & 0 & 0 & 0 & 0 & 0 & 0 & $>1000$ & $>1000$ \\
\hline Trichoderma sp. 1 & 0 & 0 & 0 & 0 & 0 & 0 & 834.14 & $>1000$ \\
\hline Mycelia sterilia 1 & 0 & 0 & 0 & 0 & 0 & 0 & $>1000$ & $>1000$ \\
\hline Mycelia sterilia 2 & 13 & 0 & 11 & 0 & 0 & 0 & $>1000$ & $>1000$ \\
\hline \multicolumn{9}{|l|}{$\begin{array}{l}\text { Portieria hornemannii } \\
\text { (Rhodophyte) }\end{array}$} \\
\hline Mycelia sterilia 3 & 0 & 0 & 0 & 0 & 0 & 0 & $>1000$ & $>1000$ \\
\hline \multicolumn{9}{|l|}{$\begin{array}{l}\text { Sargassum piluliferum } \\
\text { (Phaeophyte) }\end{array}$} \\
\hline Aspergillus fumigatus & 15 & 19 & 14 & 15 & 0 & 0 & 555.22 & 807.23 \\
\hline Fusarium sp. & 9 & 0 & 6 & 0 & 0 & 0 & 834.14 & 863.29 \\
\hline Trichoderma sp. 2 & 11 & 0 & 9 & 0 & 0 & 0 & $>1000$ & $>1000$ \\
\hline \multicolumn{9}{|l|}{$\begin{array}{l}\text { Caulerpa racemosa } \\
\text { (Chlorophyte) }\end{array}$} \\
\hline Aspergillus niger & 13 & 0 & 11 & 0 & 0 & 0 & 706.76 & 930.12 \\
\hline \multicolumn{9}{|l|}{$\begin{array}{l}\text { Enhalus acoroides } \\
\text { (Seagrass) }\end{array}$} \\
\hline Aspergillus sp. 3 & 9 & 0 & 7 & 0 & 0 & 0 & $>1000$ & $>1000$ \\
\hline Aspergillus tubingensis & 17 & 0 & 19 & 0 & 0 & 0 & 201.56 & 333.27 \\
\hline Mycelia sterilia 4 & 0 & 0 & 0 & 0 & 0 & 0 & $>1000$ & $>1000$ \\
\hline Mycelia sterilia 5 & 9 & 0 & 7 & 0 & 0 & 0 & $>1000$ & $>1000$ \\
\hline \multicolumn{9}{|l|}{$\begin{array}{l}\text { Syringodium isoetifolium } \\
\text { (Seagrass) }\end{array}$} \\
\hline Aspergillus sp. 4 & 0 & 0 & 0 & 0 & 0 & 0 & $>1000$ & $>1000$ \\
\hline Paecilomyces sp. & 0 & 0 & 0 & 0 & 0 & 0 & $>1000$ & 875.01 \\
\hline Penicillium sp. & 8 & 0 & 0 & 0 & 0 & 0 & $>1000$ & 873.90 \\
\hline Sclerotinia sp. & 9 & 0 & 9 & 0 & 0 & 0 & $>1000$ & $>1000$ \\
\hline DMSO (- control) & 0 & 0 & 0 & 0 & 0 & 0 & $>1000$ & $>1000$ \\
\hline Streptomycin (+ control) & 21 & 21 & 20 & 20 & 18 & 18 & - & - \\
\hline
\end{tabular}

media and addition of marine salts during mass production. Furthermore, all the methanolic extracts from marine aspergilli showed weak inhibition towards T. congolense (less than $40 \%$ ). The $\mathrm{IC}_{50}$ of the most bioactive crude culture extracts was determined (Tab. 3) and showed that the ethyl acetate extract of $A$. fumigatus cultivated in MEB was the most potent $\left(\mathrm{IC}_{50}: 298.18 \mathrm{ng} \mathrm{mL} \mathrm{mL}^{-1}\right)$ with selectivity index ranging from $7.21-15.50$.

\section{Discussion}

Marine-derived fungi are known colonizers of various organic substrates, including corals, echinoderms, seagrasses, algae, and vertebrates, and can act as endophytes, pathogens, saprobes, and parasites in the marine communities (Loque et al. 2010). In this study, 16 morphospecies of marine-derived fungi belonging to the genera Aspergillus, Fusarium, Paecilomyces, Penicillium, Sclerotinia, Thamnidium, and Trichoderma including five mycelia sterilia were isolated from macroalgae and seagrasses (Tab. 1). Among the MDF, the genus Aspergillus was isolated in highest frequency and in wide distribution in brown, red and green marine algae, and seagrasses. It is well-reported that Aspergillus is not only isolated from terrestrial substrata, but is also widely distributed in the marine environment (Kato et al. 2007, Cui et al. 2010, Li et al. 2011). In this study, all the isolated MDF genera were observed to be terrestrial in origin. However, it is possible for terrestrial fungi to be introduced into the marine ecosystem 


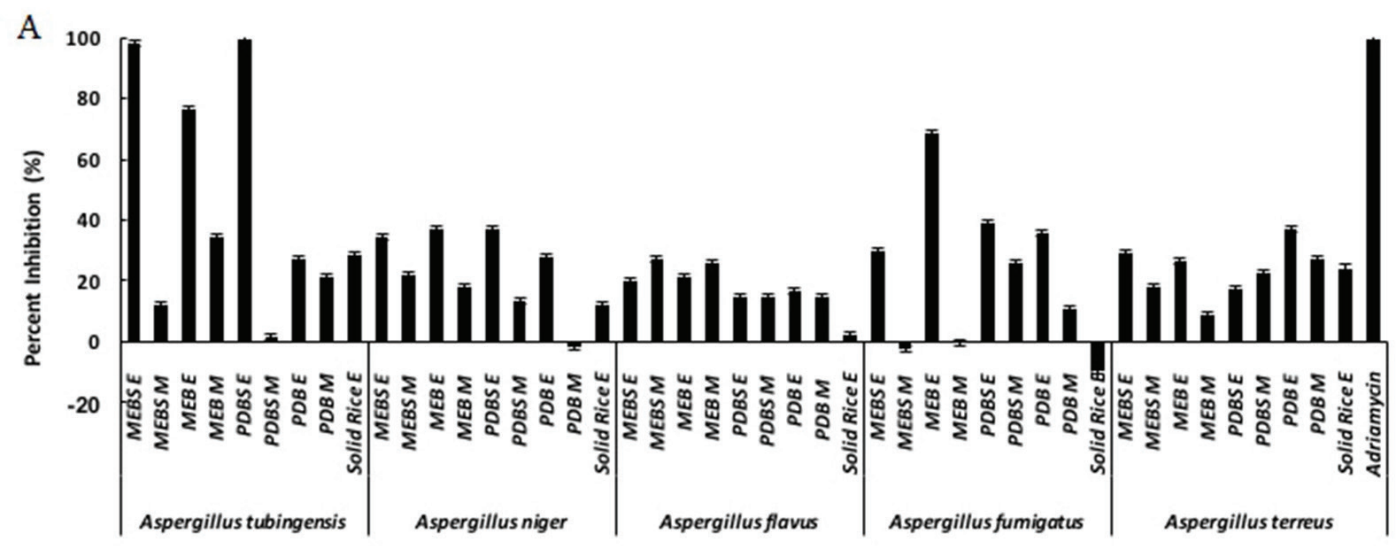

B

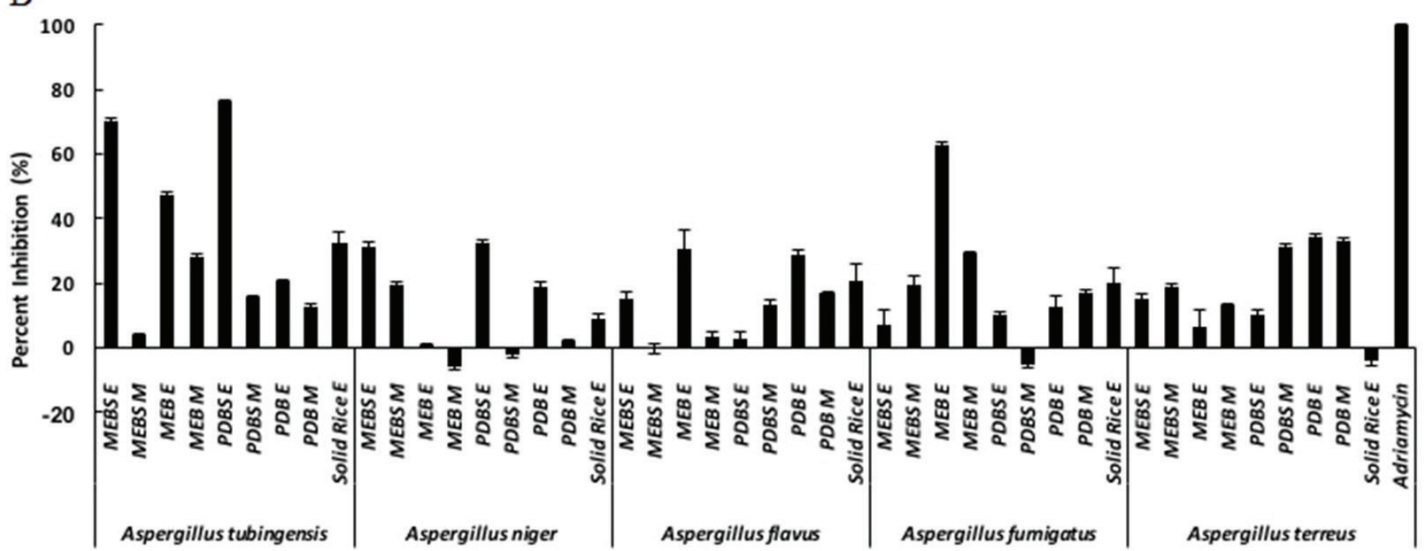

Fig. 3. Cytotoxicity profile of ethyl acetate (E) and methanolic (M) crude extracts $\left(5 \mu \mathrm{g} \mathrm{mL} \mathrm{L}^{-1}\right)$ from marine aspergilli against $\mathrm{P} 388 \mathrm{murine}$ leukemia cancer cell line (A) and HeLa cervical cancer cell line (B). Marine aspergilli were previously cultivated in malt extract broth with and without marine salt (MEB/MEBS), potato dextrose broth with and without marine salt (PDB/PDBS), and solid rice. Data are average values $\pm \operatorname{SD}(n=3)$.

Tab. 3. Median inhibitory concentration $\left(\mathrm{IC}_{50}\right)$ of ethyl acetate crude extracts from selected marine aspergilli. a Assessment of cytotoxicity: $\mathrm{IC}_{50}<30 \mu \mathrm{g} \mathrm{mL}{ }^{-1}$ signifies anticancer activity (Suffness and Pezzuto 1990). ${ }^{\mathrm{b}}$ Assessment of antiprotozoal activity: $\mathrm{IC}_{50}<10 \mu \mathrm{g} \mathrm{mL} \mathrm{m}^{-1}$ signifies trypanocidal activity (Koch et al. 2005). 'Assessment of SI value for trypanocidal activity: SI value $>2$ signifies selectivity (Koch et al. 2005).

\begin{tabular}{|c|c|c|c|c|c|}
\hline \multirow{2}{*}{ Marine aspergilli } & \multirow{2}{*}{ Culture medium } & \multicolumn{3}{|c|}{ Test organism/cell line (IC50 ng mL $\mathrm{mL}^{-1}$ ) } & \multirow{2}{*}{$\begin{array}{l}\text { Selectivity }{ }^{c} \text { index } \\
\text { (SI) }\end{array}$} \\
\hline & & P388 & $\mathrm{HeLa}^{\mathrm{a}}$ & Trypanosoma ${ }^{\mathrm{b}}$ congolense & \\
\hline Aspergillus fumigatus & MEB & 2150 & 4623 & 298.18 & $7.21-15.50$ \\
\hline Aspergillus tubingensis & MEBS & 2247 & 1168 & 381.16 & $3.06-5.90$ \\
\hline Aspergillus tubingensis & MEB & 3462 & 1857 & 2010.04 & $0.92-1.72$ \\
\hline Aspergillus tubingensis & PDBS & 1301 & 1028 & 485.58 & $2.12-2.68$ \\
\hline Adriamycin & + control & 92.85 & 72.96 & - & - \\
\hline Pentamidine & + control & - & - & 100.45 & - \\
\hline
\end{tabular}

and to evolve as a result of selective pressure from this new habitat (Jones 1994). As shown in Fig. 1, the colony extension rates of the isolated marine-derived fungi were greater in MEAS as opposed to MEA. This shows the adaptability of the MDF to the salinity in the marine environment. Following Kohlmeyer and Kohlmeyer (1979), the isolates were regarded as facultative marine fungi that might have originated from freshwater or terrestrial environment and undergone physi- ological adaptations for their survival in the marine environment. This is further supported by the ability of the MDF to grow in MEA with or without marine salt. Similar growth characteristic was observed in other marine fungi, as in the case of Dendryphiella (dela Cruz et al. 2006b).

The continuing prevalence of infectious diseases and the challenge to chemotherapy brought about by drug resistance call for the development of a new pipeline of drugs. Owing 
to their taxonomic and metabolic diversity, marine organisms including marine fungi are now considered ideal sources of new secondary metabolites (Schulz et al. 2008). Among the tested MDF, A. tubingensis and A. fumigatus conferred the greatest antibacterial and cytotoxic properties (Tab. 2). Comparing the zones of inhibition of these crude culture extracts with reference antibiotics specified by EUCAST Ver. 7 (2017), the antibacterial property of the mycelial extract of $A$. fumigatus was more potent than netilmicin while the broth extract of $A$. tubingensis showed greater inhibition than ampicillin and benzylpenicillin. This is not surprising as the observed bioactivities of the members of the genus Aspergillus are well reported (Lee et al. 2013). In fact, many novel bioactive compounds have been isolated from marine aspergilli, including waikialoid A (Wang et al. 2012) and pseudodeflectusin (Ogawa et al. 2004). However, the other isolated MDF (Fusarium, Paecilomyces, Penicillium, Sclerotinia, Thamnidium, and Trichoderma) showed either no bioactivities or fewer than marine aspergilli, which further supports the idea that marine aspergilli are worthy target microorganisms for drug discovery. Interestingly, a higher record of bioactivity was observed in the ethyl acetate extracts derived from the culture broth as opposed to the methanolic extracts derived from the mycelia. This means that the bioactive metabolites must have been extracellularly produced by the MDF. Thrane et al. (2007) explained that most of the secondary metabolites, organic acids, enzymes, and other bioactive proteins are extracellularly produced by the fungi to their environment.

Based on the initial screening, the marine aspergilli $A$. tubingensis, A. fumigatus, A. niger, A. terreus, and A. flavus were selected for further testing against cancer cells and the protozoan T. congolense. Consistent with the previous results, A. fumigatus and A. tubingensis showed the greatest anticancer and trypanocidal activities (Tab. 3). The study reported for the first time the bioactivity of a marine-derived A. fumigatus against T. congolense. Previous studies reported the isolation of $A$. fumigatus from macroalgae, sea sediment, and holothurians, and showed to produce several cytotoxic compounds such as N-acetyltyramine (Zhao et al. 2010) and the apoptosis-inducing metabolite fumigaclavine $\mathrm{C}$ ( $\mathrm{Li}$ et al. 2013). Moreover, Furtado et al. (2005) also reported that $A$. fumigatus derived from soil samples produced metabolites that are bioactive against T. cruzi, which causes Chagas disease. Another promising bioactive MDF is A. tubingensis, which was found to be cytotoxic against HeLa and P388. The isolation and the possible mode of action of its bioactive compound is fully discussed in a separate paper (Notarte et al. 2017). Nonetheless, the cytotoxicity of A. tubingensis is supported by Zhan et al. (2007) when a terrestrial strain derived from the rhizosphere of Festuca paradoxa produced metabolites that were active against several cancer cells.

The 'OSMAC (one strain-many compounds) approach', which involves manipulation of cultivation parameters, such as the media composition, is an efficient strategy for enhancing the chemical diversity of compounds that may be of interest as lead structures in conducting high-throughput biological screening (Bode et al. 2002). Wang et al. (2014) demonstrated the potential application of the OSMAC approach that induced the MDF Ascotricha sp. to synthesize three new caryophyllene derivatives when cultured in an oligotrophic rather than the typical eutrophic medium. In the current research, there was no general pattern on the influence of marine salt on the bioactivities of marine aspergilli, although some species were directly influenced by salinity in the production of bioactive metabolites (Figs. 3 and 4). Interestingly, cultivation in solid rice led to a weaker or loss

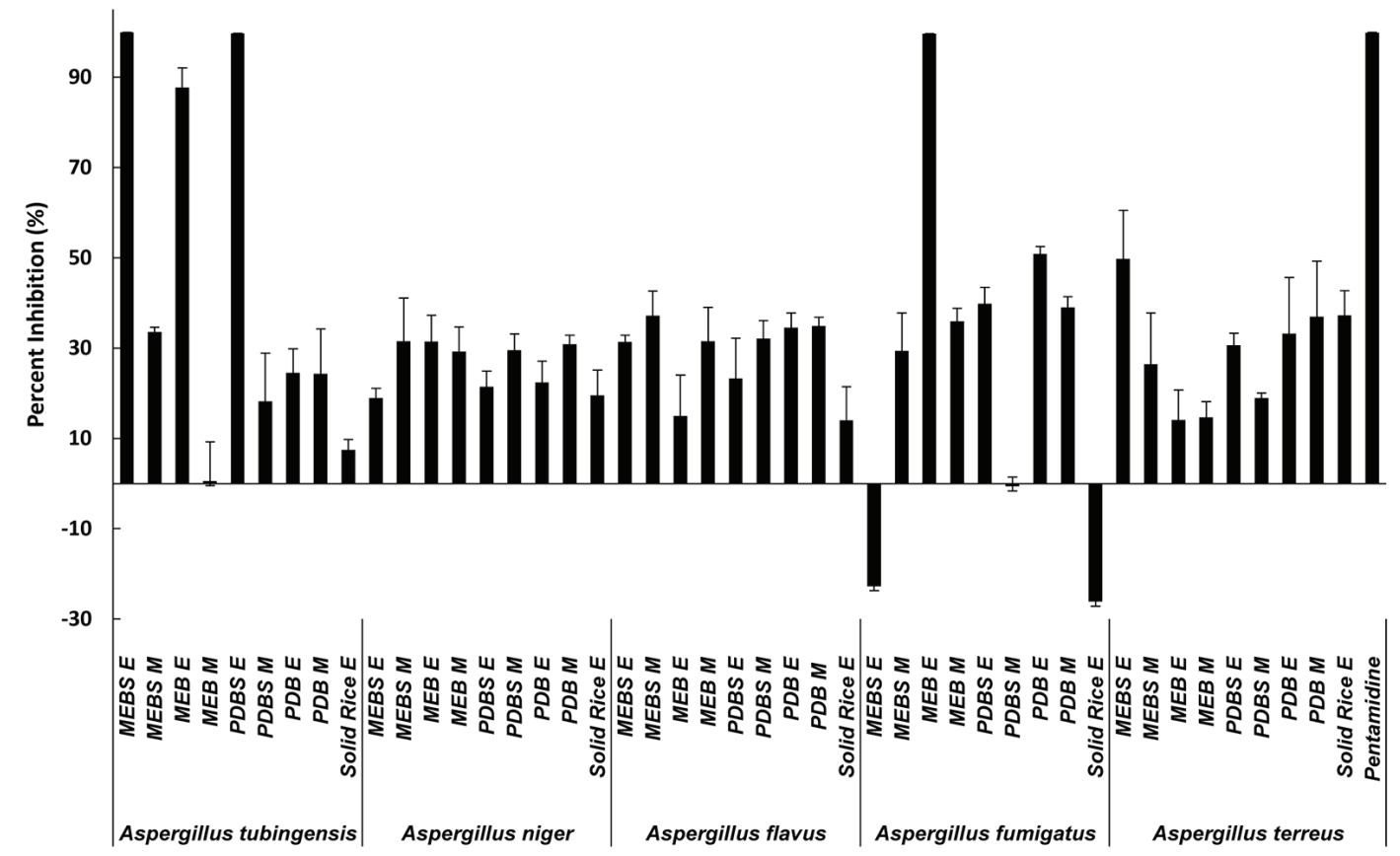

Fig. 4. Trypanocidal activity of ethyl acetate (E) and methanolic (M) crude extracts $\left(2.5 \mu \mathrm{g} \mathrm{mL}^{-1}\right)$ from marine aspergilli cultivated in malt extract broth with and without marine salt (MEB/MEBS), potato dextrose broth with and without marine salts(PDB/PDBS), and solid rice. Data are average values $\pm S D(n=2)$. 
of bioactivity for the marine aspergilli. Indeed, it is worth noting that $A$. tubingensis proved to have elicited better bioactivities against cancer cells and T. congolense when cultivated in the presence of marine salt regardless of the culture medium used for cultivation. This indicates that salt plays an important role in the synthesis of biologically active components present in the crude extracts of $A$. tubingensis. The crucial role of salt in the production of compounds was best demonstrated by Wang et al. (2011) when cultivation of the marine-derived fungus Spicaria elegans in 10\% salinity led to the production of novel and chlorinated compounds that were not synthesized when the same fungus was cultured in $3 \%$ saline condition. Another interesting observation is that of $A$. fumigatus, which showed promising cytotoxic and trypanocidal activities only when cultivated in MEB without marine salt. Calvo et al. (2002) showed that the type of carbon and nitrogen source used as precursor molecules during anabolic chemical reactions affects the synthesis of certain compounds. As in the case of MEB, this culture medium

\section{References}

Bugni, T. S., Ireland, C. M., 2004: Marine-derived fungi: A chemically and biologically diverse group of microorganisms review. Natural Product Reports 16, 143-163.

Bode, H. B., Bethe, B., Höfs, R., Zeeck, A., 2002: Big effects from small changes: Possible ways to explore nature's chemical diversity. ChemBioChem 3, 619-627.

Calvo, A. M., Wilson, R. A., Bok, J. W., Keller, N. P., 2002: Relationship between secondary metabolism and fungal development. Microbiology and Molecular Biology Reviews 66, 447-459.

Cui, C. M., Li, X. M., Meng, L., Li, C. S., Huang, C. G., Wang, B. G., 2010: 7-norergosterolide, a pentalactone-containing norsteroid and related steroids from the marine-derived endophytic Aspergillus ochraceus EN-31. Journal of Natural Products $73,1780-1784$.

dela Cruz, T. E. E., Wagner, S., Schulz, B., 2006a: Physiological responses of marine Dendryphiella species from different geographical locations. Mycological Progress 5, 108-119.

dela Cruz, T. E. E., Schulz, B. E., Kubicek, C. P., Druzhinina, I. S., 2006b: Carbon source utilization by the marine Dendryphiella species D. arenaria and D. salina. FEMS Microbiology Ecology 58, 343-353.

European Committee on Antimicrobial Susceptibility Testing [EUCAST], 2017: Routine and extended internal quality control for MIC determination and disk diffusion as recommended by EUCAST. Retrieved from http://www.eucast.org.

Furtado, N. A. J. C., Duarte, M. C. T., de Albuquerque, S., Mello, C., Bastos, J. K., 2005: Improvement of trypanocidal metabolites production by Aspergillus fumigatus using neural networks. Microbiological Research 160, 141-148.

Gao, S. S., Li, X. M., Li, C. S., Proksch, P., Wang, B. G., 2011: Penicisteroids $\mathrm{A}$ and $\mathrm{B}$, antifungal and cytotoxic polyoxygenated steroids from the marine alga-derived endophytic fungus Penicillium chrysogenum QEN-24S. Bioorganic and Medicinal Chemistry Letters 16, 2894-2897.

Gerwick, W. H., Moore, B. S., 2012: Lessons from the past and charting the future of marine natural products drug discovery and chemical biology. Chemistry and Biology 19, 85-98.

Glass, N. L., Donaldson, G. C., 1995: Development of primer sets designed for use with the PCR to amplify genes from filamen- contains malt extract and peptone, which served as the carbon and nitrogen sources for the production of various metabolites by A. fumigatus. Moreover, the production of bioactive chemicals from $A$. fumigatus without marine salt may suggest that the presence of salt could block the expression of certain biosynthetic pathways essential for the synthesis of its bioactive components. As described by Yu and Keller (2005), salinity is one factor that can regulate production of secondary metabolites.

\section{Acknowledgements}

The authors would like to extend their modest gratitude to Dr. Paciente A. Cordero, Jr. for the identification of marine algae and seagrasses, to Dr. Irineo J. Dogma, Jr. for aid in the morphological identification of fungi, and to the Research Center for Natural and Applied Sciences of the University of Santo Tomas. KIR Notarte acknowledges the Department of Science and Technology - Science Education Institute for the graduate scholarship and research grant. tous ascomycetes. Applied and Environmental Microbiology 61, 1323-1330.

Greve, H., Schupp, P. J., Eguereva, E., Kehraus, S., Kelter, G., Maier, A., 2008: Apralactone A and a new stereochemical class of curvularins from the marine fungus Curvularia sp. European Journal of Organic Chemistry 2008, 5085-5092.

Jones, E. B. G., 1994: Ultrastructure and taxonomy of the aquatic ascomycetes order Halosphaeriales. Canadian Journal of Botany 73, 790-801.

Kato, H., Yoshida, T., Tokue, T., Nojiri, Y., Hirota, H., Ohta, T., Williams, R. M., Tsukamoto, S., 2007: Notoamides A-D: Prenylated indole alkaloids isolated from a marine-derived fungus, Aspergillus sp. Angewandte Chemie International Edition in English 46, 2254-2256.

Klinch, M. A., 2002: Identification of common Aspergillus species. Centraalbureau voor Schimmelcultures, Netherlands.

Koch, A., Tamez, P., Pezzuto, J., Soejarto, D., 2005: Evaluation of plants used for antimalarial treatment by the Maasai of Kenya. Journal of Ethnopharmacology 101, 95-99.

Kohlmeyer, J., Kohlmeyer, E., 1979: Marine mycology. Academic Press, New York.

Lee, Y. M., Kim, M. J., Li, H., Zhang, P., Bao, B., Lee, K. J., Jung, J. H., 2013: Marine-derived Aspergillus species as a source of bioactive secondary metabolites. Marine Biotechnology 15, 499-519.

Li, J. L., Lee, Y. M., Hong, J., Bae, K. S., Choi, J. S., Jung, J. H., 2011: A new antioxidant from the marine sponge-derived fungus Aspergillus versicolor. Natural Product Sciences 17, 14-18.

Li, Y. X., Himaya, S. W. A., Dewapriya, P., Zhang, C., Kim, S. K., 2013: Fumigaclavine $C$ from a marine-derived fungus Aspergillus Fumigatus induces apoptosis in MCF-7 breast cancer cells. Marine Drugs 11, 5063-5086.

Lin, A., Lu, X., Fang, Y., Zhu, T., Gu, Q., Zhu, W., 2008: Two new 5-hydroxy-2-pyrone derivatives isolated from a marine-derived fungus Aspergillus flavus. The Journal of Antibiotics 61, 245-249.

Loque, C. P., Medeiros, A. O., Pellizzari, F. M., Oliveira, E. C., Rosa, C. A., 2010: Fungal community associated with marine macroalgae from Antarctica. Polar Biology 33, 641-648. 
Meyer, B., Ferrighi, N., Putnam, J., Jacobsen, L., Nichols, D., McLaughlin, J., 1982: Brine shrimp: A convenient general bioassay for active plant constituents. Planta Medica 45, 31-34.

Miao, F. P., Li, X. D., Liu, X. H., Cichewicz, R. H., Ji, N. Y. 2012: Secondary metabolites from an algicolous Aspergillus versicolor strain. Marine Drugs 10, 131-139.

Notarte, K. I., Nakao, Y., Yaguchi, T., Bungihan, M., Suganuma, K., Dela Cruz, T. E., 2017: Trypanocidal activity, cytotoxicity and histone modifications induced by malformin $\mathrm{A}_{1}$ isolated from the marine-derived fungus Aspergillus tubingensis IFM 63452. Mycosphere 8, 111-120.

Ogawa, A., Mukarami, C., Kamisuki, S., Kuriyama, I., Yoshida, H., Sugawara, F., Mizushina, Y., 2004: Pseudodeflectusin, a novel isochroman derivative from Aspergillus pseudodeflectus a parasite of the seaweed, Sargassum fusiform, as a selective human cancer cytotoxin. Bioorganic and Medicinal Chemistry Letters 14, 3539-3543.

Quimio, T. H., 1988: Illustrated Philippine fungi. National Bookstore, Manila.

Quinto, E., Santos, M., 2005: Microbiology. In: Guevara, B. Q., (ed.), A guidebook to plant screening: Phytochemical and biological. University of Santo Tomas Publishing House, Manila.

Raper, K. B., Fennell, D. I., 1977: The genus Aspergillus. Robert E. Krieger Publishing Co., New York.

Schulz, B., Draeger, S., dela Cruz, T. E. E., Rheinheimer, J., Siems, K., Loesgen, S., Bitzer, J., Schloerke, O., Zeeck, A., Kock, I., Hussain, H., Dai, J., Krohn, K. 2008: Screening strategies for obtaining novel, biologically active fungal secondary metabolites from marine habitats. Botanica Marina 51, 169-234.

Silber, J., Kramer, A., Labes, A., Tasdemir, D., 2016: From discovery to production: Biotechnology of marine fungi for the production of new antibiotics. Marine Drugs 14, 1-20.

Solis, M. J. L., Draeger, S., dela Cruz, T. E. E., 2010: Marine-derived fungi from Kappaphycus alvarezii and K. striatum as potential causative agents of ice-ice disease in farmed seaweeds. Botanica Marina 53, 587-594.

Suffness, M., Pezzuto, J. M., 1990: Assays related to cancer drug discovery. In: Hostettmann, K., (ed.), Methods in plant biochemistry: Assays for bioactivity. Academic Press, London.

Suganuma, K., Allamanda, P., Hakimi, H., Zhou, M., Angeles, J. M., Kawazu, S., Inoue, N., 2014: Establishment of ATP-based luciferase viability assay in 96-well plate for Trypanosoma congolense. The Journal of Veterinary Medical Science 76, 14371441.

Supaphon, P., Phongpaichit, S., Rukachaisirikul, V., Sakayaroj, J. 2013: Antimicrobial potential of endophytic fungi derived from three seagrass species: Cymodocea serrulata, Halophila ovalis and Thalassia hemprichii. PLOS ONE 8, 1-9.

Supaphon, P., Phongpaichit, S., Rukachaisirikul, V., Sakayaroj, J., 2014: Diversity and antimicrobial activity of endophytic fungi isolated from the seagrass Enhalus acoroides. Indian Journal of Geo-Marine Sciences 43, 785-797.

Takada, Y., Umehara, M., Katsumata, R., Nakao, Y., Kimura, J., 2012: The total synthesis and structure-activity relationships of a highly cytotoxic depsipeptide kulokekahilide- 2 and its analogs. Tetrahedron 68, 659-669.

Thrane, U., Andersen, B., Frisvad, J. C., Smedsgaard, J., 2007: The exo-metabolome in filamentous fungi. In: Nielsen, J., Hewitt, J., (eds.), Metabolomics: A powerful tool in systems biology. Springer, Berlin.

Wang, W. J., Li, D. Y., Li, Y. C., Hua, H. M., Ma, E. L., Li, Z. L., 2014: Caryophyllene sesquiterpenes from the marine-derived fungus Ascotricha sp. ZJ-M-5 by the one strain-many compounds strategy. Journal of Natural Products 77, 1367-1371.

Wang, X., You, J., King, J. B., Powell, D. R., Cichewicz, R. H., 2012: Waikialoid A suppresses hyphal morphogenesis and inhibits biofilm development in pathogenic Candida albicans. Journal of Natural Products 75, 707-715.

Wang, Y., Lu, Z., Sun, K., Zhu, W., 2011: Effects of high salt stress on secondary metabolite production in the marine-derived fungus Spicaria elegans. Marine Drugs 9, 535-542.

Yu, J. H., Keller, N., 2005: Regulation of secondary metabolism in filamentous fungi. Annual Review of Phytopathology 43, 437-458.

Zhan, J., Gunaherath, G. M. K. B., Wijeratne, E. M. K., Gunatilaka, A. A. L., 2007: Asperpyrone D and other metabolites of the plant-associated fungal strain Aspergillus tubingensis. Phytochemistry 68, 368-372.

Zhao, W. Y., Zhu, T. J., Fan, G. T., Liu, H. B., Fang, Y. C., Gu, Q. Q., Zhu, W. M., 2010: Three new dioxopiperazine metabolites from a marine-derived fungus Aspergillus fumigatus Fres. Natural Product Research 24, 953-957. 